\title{
Tubulointerstitial injury and proximal tubule albumin transport in early diabetic nephropathy induced by type 1 diabetes mellitus
}

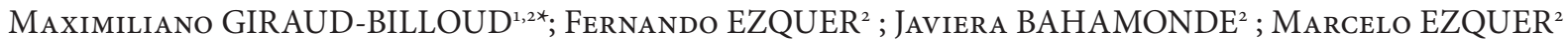 \\ ${ }^{1}$ IHEM, Universidad Nacional de Cuyo, CONICET, Facultad de Ciencias Médicas, Mendoza, Argentina. \\ ${ }^{2}$ Centro de Medicina Regenerativa, Facultad de Medicina Clínica Alemana, Universidad del Desarrollo, Avenida Las Condes 12438, Santiago, Chile
}

Key words: Albuminuria, Megalin, Cubilin, Autophagy.

\begin{abstract}
A decrease in the tubular expression of albumin endocytic transporters megalin and cubilin has been associated with diabetic nephropathy, but there are no comprehensive studies to date relating early tubulointerstitial injury and the effect of the disease on both transporters in type 1 diabetes mellitus (T1DM). We used eight-weekold male C57BL/6 mice divided into two groups; one of them received the vehicle (control group), while the other received the vehicle $+200 \mathrm{mg} / \mathrm{kg}$ streptozotocin (T1DM). Ten weeks after the injection, we evaluated plasma insulin, enzymuria, urinary vitamin D-binding protein (VDBP), tubulointerstitial fibrosis and proximal tubule histology, markers of autophagy, and megalin and cubilin levels. We found a reduction in tubular protein reabsorption (albumin and VDBP as specific substances carried by both transporters) with increased tubulointerstitial injury, development of fibrosis, thickening of tubular basement membrane, and an increase in tubular cell metalloproteases. This was associated with a decrease in the renal expression of megalin and cubilin. We also observed an increase in the amount of cellular vesicles of the phagocytic system in the tubules, which could be linked to an alteration of normal intracellular trafficking of both receptors, thus affecting the normal function of transporters in early stages of diabetic nephropathy. In diabetic animals, the added effects of tubulointerstitial injury, the decreases in megalin and cubilin expression, and an altered intracellular trafficking of these receptors, seriously affect protein reabsorption.
\end{abstract}

\section{Introduction}

Diabetic nephropathy is one of the major causes of chronic kidney disease worldwide and is defined as a rise in the urinary albumin excretion rate with abnormal renal function (Gross, JL et al., 2005). Early proteinuria in diabetic nephropathy involves glomerular and tubular alterations (Gibb, D et al., 1989), with albuminuria (micro- to macroalbuminuria) being one of the central markers of disease progression (Moresco, RN et al., 2013). Diabetes mellitus encompasses structural changes in all compartments of the kidney. An increase in the amount of renal interstitium correlates with an alteration of the glomerular filtration rate and is indicative of disease progression in type 1 diabetes mellitus (T1DM) (Lane, $\mathrm{PH}$ et al., 1993; White, KE \& Bilous, RW, 2000).

\footnotetext{
*Address correspondence to: Maximiliano Giraud-Billoud, mgiraudbilloud@gmail.com

Received: January 22, 2016. Revised version received: May 23,

2016. Accepted: May 26, 2016.
}

Until now, much has been learned about the role of the glomerulus and vasculature in the pathogenesis of diabetic nephropathy, and the role of tubulointerstitial changes in early diabetic nephropathy have recently received growing attention (Kanwar, YS et al., 2008; Loeffler, I, 2012; Vallon, V \& Thomson, SC, 2012; Vallon, V, 2014).

The initial phase of diabetic nephropathy is characterized by kidney hyperplasia followed by hypertrophy with elevated glomerular filtration rate (Blantz, RC \& Singh, P, 2014). Likewise, tubular growth explains the hyper-reabsorption observed at early stages of diabetic nephropathy and contributes to glomerular hyper-filtration and the progression of renal disease to tubulointerstitial inflammation and fibrosis (Vallon, V, 2011; Vallon, V \& Thomson, SC, 2012). Disease progression also correlates with tubular hypertrophy (Huang, H-C \& Preisig, PA, 2000; Amiri, F et al., 2002; Efendiev, R et al., 2003) and differentiation of tubulointerstitial cells into extracellular matrix-producing myofibroblasts (Kanasaki, $\mathrm{K}$ et al., 2013), with the formation of atubular glomeruli and interstitial fibrosis (Meyer, TW, 2003). 
Normally, around 95\% of filtered albumin is reabsorbed in the proximal tubule (Bourdeau, J \& Carone, F, 1974). The most important endocytic retrieval pathway is mediated by the action of two protein binding receptors: megalin and cubilin (Christensen, EI \& Birn, H, 2001; Christensen, EI et al., 2012).

Megalin $(\approx 600 \mathrm{KDa})$ is a transmembrane glycoprotein expressed in the brush border membrane and endocytic apparatus of the proximal tubule. This protein is the main transporter for endocytosis of albumin and other low molecular weight proteins, such as vitamin D-binding protein (VDBP) (Christensen, EI et al., 2012). Cubilin ( $\approx 460$ $\mathrm{KDa}$ ) is a cooperating extracellular glycoprotein anchored to the tubular cell surface. This transporter is the main receptor for large molecular weight proteins and interacts with megalin, regulating its endocytic function (Christensen, EI et al., 2012). The interaction between both receptors is important because megalin mediates the internalization of cubilin and its ligands (Hammad, SM et al., 2000). However, cubilin can form a functional complex with amnionless called CUBAM, which is translocated to the plasma membrane and displays megalin-independent activity (Coudroy, G et al., 2005; Christensen, EI et al., 2012; Christensen, EI et al., 2013). At the cellular level, megalin and cubilin are present in microvilli, coated pits, and subsequent compartments of the endocytic route. However, before entering lysosomes, the majority is recycled to the apical membrane (Christensen, EI et al., 2012). Both albumin transporters have been postulated as mediators that participate in renal disease (Christensen, EI et al., 2012), but the underlying pathogenic mechanisms remain unclear (Nielsen, R et al., 2016). The overload of tubular proteins and the alteration of tubular albumin receptors have a deleterious effect in the cells and have been associated with the presence of proinflammatory and profibrotic mediators that lead cells to apoptosis and tissue damage (Abbate, M et al., 2006; Caruso-Neves, C et al., 2006). Likewise, changes in the expression of these receptors have been reported in chronic diseases such as hypertension and diabetes (Tojo, A et al., 2003; Thrailkill, KM et al., 2009; Whaley-Connell, A et al., 2011; Ogasawara, S et al., 2012). Increased urinary excretion of megalin and cubilin has been found in human diabetic patients (Thrailkill, KM et al., 2009; Ogasawara, S et al., 2012), which could be related to a process called "regulated intramembrane proteolysis", where metalloproteases (MMP) cause shedding of the receptor's ectodomain (Biemesderfer, D, 2006; Christensen, EI et al., 2012).

As far as we know, there are no comprehensive studies regarding the effect of tubulointerstitial injury induced by T1DM on the expression and function of the albumin endocytic transporters megalin and cubilin. Therefore, considering that diabetes is a multifactorial disease and that glomerular alterations are well characterized and play an important role in the development of albuminuria, we focus our study on the role of the tubule in a murine model of early diabetic nephropathy induced by T1DM. The specific aims of our study were (1) to evaluate the expression and function of megalin and cubilin during tubulointerstitial injury, and (2) to explore the possible pathogenic factors related to the alteration of these transporters, with special focus on autophagy.

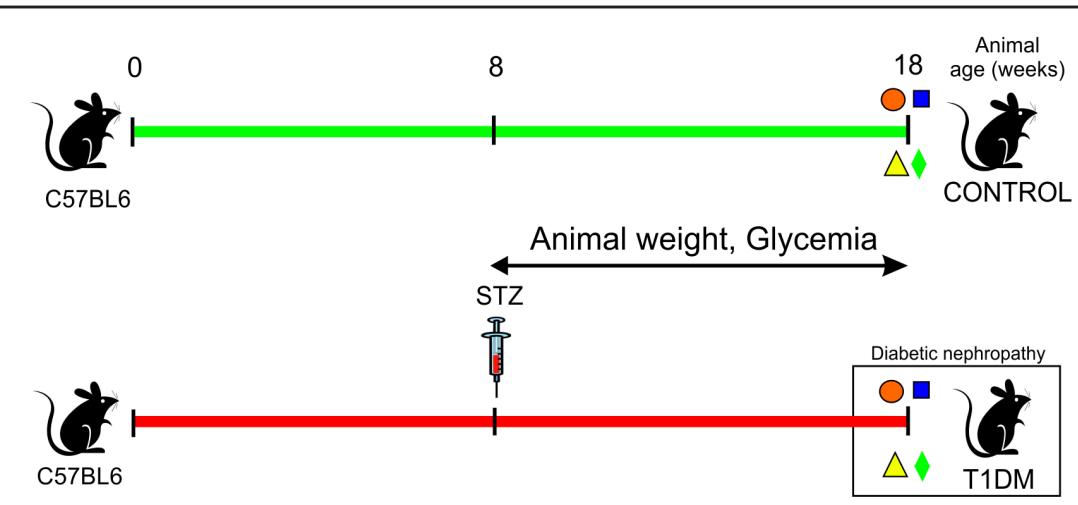

Plasma insulin (ELISA), enzymuria, urinary VDBP and albumin (ELISA and IFI)

Tubulointerstitial fibrosis evaluation (Masson and IFI of $\alpha-S M A$ )

Tubular ultrastructure and autophagy evaluation (TEM and IFI of LBPA)

$\triangle$ Megalin and cubilin levels (IFI, RT-qPCR, WB)
FIGURE 1. Experimental design. During the evolution of the disease, all animals were weighed and blood glucose was controlled every two weeks. After the development of diabetic nephropathy (10 weeks after STZ administration), renal function and structure were evaluated. TIDM, type 1 diabetes mellitus; STZ, streptozotocin; VDBP, vitamin D-binding protein; a-SMA, alpha-smooth muscle actin LBPA: lysobisphosphatidic acid, TEM: transmission electron microscopy. 


\section{Materials and Methods}

\section{Animals}

Male C57BL/6 mice (Jackson Laboratory) were housed at constant temperature $\left(22 \pm 2{ }^{\circ} \mathrm{C}\right)$ and $60 \%$ relative humidity, with a 12:12 h light-dark cycle and unrestricted access to a standard rodent diet and autoclaved water. When required, animals were slightly anaesthetized with sevoflurane (Abbott, Japan) or ketamine (Drag Pharma) plus xylazine (Centrovet). All procedures were in accordance with the Ethics Committee of Facultad de Medicina, Clínica Alemana-Universidad del Desarrollo and Animal Welfare Assurance Publications A54427-01, Office for Protection from Research Risks, Division of Animal Welfare, NIH (National Institute of Health), Bethesda, MD, USA.

\section{Induction of type 1 diabetes and sample collection}

Eight-week-old male C57BL/6 mice were slightly anesthetized and received, via intraperitoneal injection, $200 \mathrm{mg} /$ $\mathrm{kg}$ streptozotocin (STZ; Sigma-Aldrich) in $0.1 \mathrm{M}$ at $\mathrm{pH} 4.5$ (T1DM mice) or citrate buffer only (control mice) (Fig. 1). This protocol of STZ administration causes massive cytotoxic destruction of insulin producing cells, generating severe hypoinsulinemic/hyperglycemic conditions and the development of diabetic nephropathy (Breyer, MD et al., 2005; Ezquer, F et al., 2009). This experimental model of diabetic nephropathy has been characterized in our laboratory and a discrete acute nephrotoxic effect has been observed after STZ administration, with no evidence of glomerular or tubular histopathological alterations (Katoh, M et al., 2000; Tay, YC et al., 2005; Ezquer, F et al., 2015).
Therefore, this animal model of diabetes mellitus has been previously recommended as an experimental model of early diabetic nephropathy (Breyer, MD et al., 2005; Tesch, GH \& Nikolic-Paterson, DJ, 2006; Alpers, CE \& Hudkins, KL, 2011). After 10 weeks of disease evolution, diabetic animals were sacrificed along with their corresponding controls.

Urine collection and physical and biochemical determinations were made every two weeks up to the end of the study, when the animals were euthanized and plasma and kidney samples were obtained. For urine collection, mice were kept in metabolic cages for morning spot urine collection after they spontaneously urinated (Ezquer, F et al., 2009). Samples were centrifuged to remove any suspended particles and the supernatants were used for the determination of albumin, VDBP, and the enzymes alkaline phosphatase (ALP) and gamma-glutamyl transferase (GGT). After sacrifice, one kidney was fixed in $4 \%$ paraformaldehyde solution for immunohistochemical assessment, while the other was divided into two cortex sections and flash-frozen for gene expression analysis, Western blot, and ELISA detections.

\section{Physical and biochemical determinations}

Body weight, kidney weight, renal mass index (determined by the ratio of kidney weight to body weight), and biochemical parameters were measured during the experiments. Blood glucose levels were measured with a glucometer (ACCU-CHEK II; Roche Diagnostics, USA). Insulin plasma levels were measured using a mouse-specific insulin ELISA kit (Ultrasensitive Mouse Insulin ELISA, Mercodia, Sweden). Albuminuria was determined using a mouse-specific albumin ELISA kit (Albuwell, Exocell, USA)
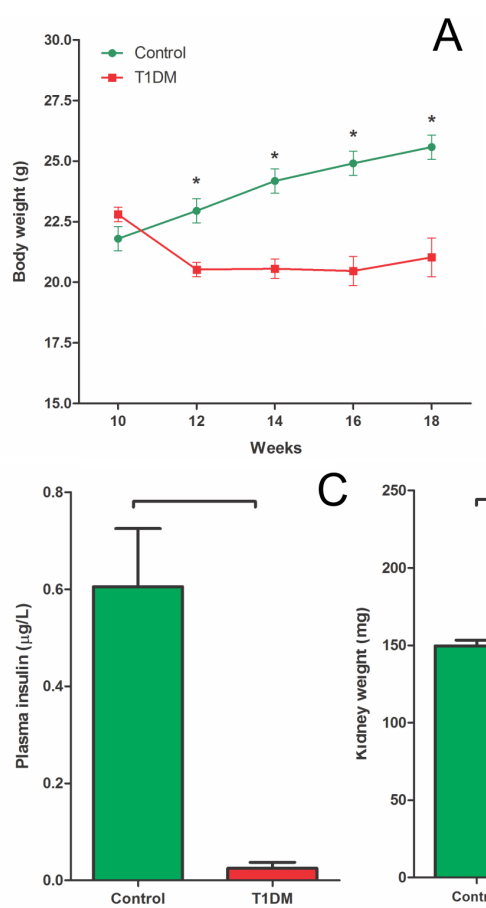

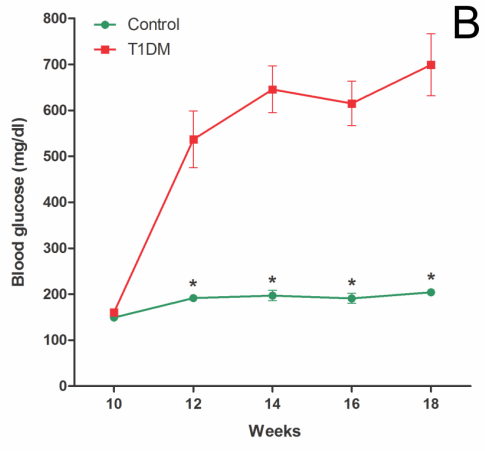

$E$

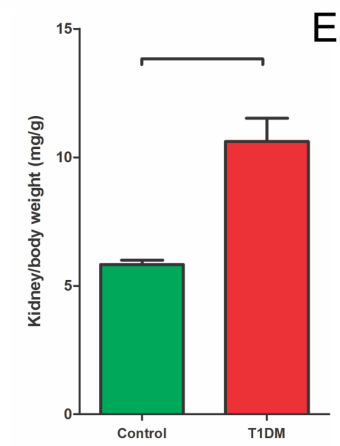

FIGURE 2. Physical and biochemical parameters of control and TIDM animals after 10 weeks of diabetes. (A) Body weight. (B) Blood glucose determinations of venous blood samples obtained from alert nonfasted animals. (C) Plasma insulin levels determined in venous blood samples obtained from the same animals at the end of the experiment. ( $C$ and $E$ ) Animal kidney weight and renal mass index (ratio of kidney weight to body weight) for experimental groups. Values are mean $\pm S E M, N=6$. Significant differences between diabetic and control animals are indicated with asterisks or horizontal brackets (Student's t-test, $\mathrm{P}<0.05$ ). 
as a specific marker of diabetic nephropathy development. Urine creatinine concentration was determined using the Creatinine Companion kit (Exocell, USA). The presence of VDBP in the urine was measured using a mouse-specific VDBP ELISA kit (BIOMATIK, USA) as a specific marker of megalin and cubilin function. Urinary alkaline phosphatase (ALP) was measured according to the International Federation of Clinical Chemistry and Laboratory Medicine (IFCC) kinetic method (Tietz, N et al., 1983) and urinary gamma-glutamyl transferase (GGT) was measured according to the Deustche Gesellschaft für Klinische Chemie (DGKC) kinetic method (Szasz, G, 1969). Both enzymes were used as markers of proximal tubule cell damage because damaged cells release ALP and GGT into urine (Raab, WP, 1972; Hong, CY \& Chia, KS, 1998). Protein concentrations were determined according to Bradford (1976). Urinary ALP, GGT, albumin, and VDBP were normalized to urine creatinine concentration.

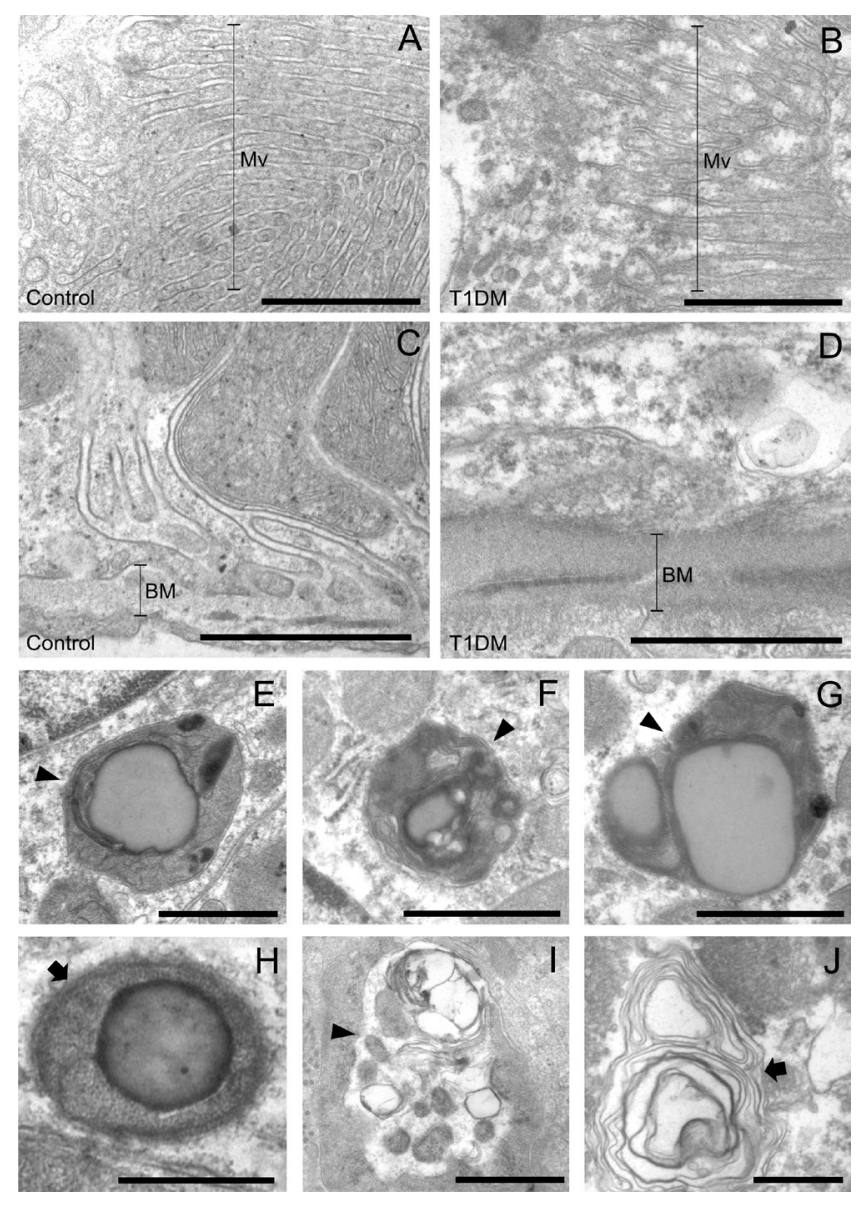

FIGURE 3. Electron microscopy assessment of proximal tubules of control (A and C) and TIDM animals (B, D, E-J). (A and B) Surface of epithelial cells and their microvilli (Mv). (C and D) Tubular basement membranes (BM) of both experimental groups. (E-J) Double membrane structures containing undigested cytoplasmic material (arrowheads) and secondary lysosomes and late endosomes (arrows) that correspond to phagocytic structures from tubular cells of T1DM animals. Scale bars: A-G and I: 1 $\mu \mathrm{m} ; \mathrm{H}$ and J: $0.5 \mu \mathrm{m}$.

\section{Histochemical analysis}

For the evaluation of tubulointerstitial fibrosis, we analyzed interstitial collagen deposition by a modified point-counting technique (Møller, JC \& Skriver, E, 1985) on tissue sections stained following the Masson Trichrome method. The relative volume $(\mathrm{Vv})$ of collagen deposition was expressed as the mean percentage of grid points lying within the interstitial area in up to ten fields in the renal cortex. All consecutive fields of renal cortex were randomly selected and photographed at 400X. A 10x10 grid was superimposed on each photograph (Photoshop ${ }^{\circledR}$ software) and 1000 points were evaluated in each case. The number of points overlaying tubular basement membranes and collagen interstitial deposits were counted, while points falling on glomerular structures or peritubular capillaries were excluded from the total count.

\section{Transmission electron microscopy (TEM)}

One- or two-millimeter-thick slices of kidney cortex were obtained and fixed for $5 \mathrm{~h}$ in a $4 \%$ paraformaldehyde- $2.5 \%$ glutaraldehyde mixture in $0.1 \mathrm{M}$ sodium phosphate buffer at $\mathrm{pH} 7.4$ and washed three times (10 minutes each) with the same buffer. The samples were post-fixed overnight with $1 \%$ osmium tetroxide and $2 \%$ uranyl acetate for 45 minutes and subsequently dehydrated via graded ethanol and acetone before being embedded in Spurr's resin. Ultrathin sections were obtained, the contrasted sections (uranyl acetate and lead citrate) were examined with a Zeiss 902 microscope, and digital micrographs were taken.

\section{Immunofluorescence (IFI) analysis}

Tissue sections 4- $\mu$ m-thick were deparaffinized in NeoClear (Merck), rehydrated and incubated in $10 \mathrm{mM}$ citrate buffer at $\mathrm{pH} 6$, in a boiling water bath for 40 minutes, for antigen retrieval. The sections were then washed three times in tris-buffered saline and Tween 20 (0.1\%) (TBS-T) for 10 minutes each, pre-incubated in blocking solution ( $5 \%$ goat or fetal bovine serum in PBS) for 60 minutes, washed three times in TBS-T and then incubated with primary antibody in TBS-T overnight at $4^{\circ} \mathrm{C}$. The primary antibodies used were: alpha-smooth muscle actin (a-SMA, ab5694, AbCAM), megalin (sc-16478, Santa Cruz), cubilin (sc-20609, Santa Cruz), lysobisphosphatidic acid (LBPA, Molecular Probes), albumin (NB110-16329, Novus Biologicals), and matrix metalloproteinase 2 (MMP-2, sc-6838, Santa Cruz). Each section was then washed three times in TBS-T and incubated with a secondary antibody in TBS-T for 60 minutes at room temperature. Donkey anti-goat Alexa-Fluor 555 conjugated serum (Invitrogen) or Goat Anti-rabbit Alexa Fluor (R) 555 (Molecular Probes) were used as secondary antibodies. After washing the sections three times with TBS-T, they were counterstained with 4,6-diamidino-2-phenylindole 
TABLE 1

RT-PCR specific primers and characteristics of amplicons

\begin{tabular}{|c|c|c|c|c|c|}
\hline \multirow[b]{2}{*}{ Gene } & \multirow{2}{*}{$\begin{array}{c}\mathrm{N}^{\circ} \text { GenBank } \\
\text { access }\end{array}$} & \multirow[b]{2}{*}{ Sence $\left(5^{\prime} \rightarrow 3^{\prime}\right)$} & \multirow[b]{2}{*}{ Antisence $\left(5^{\prime} \rightarrow 3^{\prime}\right)$} & \multicolumn{2}{|c|}{ Amplicon } \\
\hline & & & & $\begin{array}{l}\text { Size } \\
(b p)\end{array}$ & $\begin{array}{l}\mathrm{Tm} \\
\left({ }^{\circ} \mathrm{C}\right)\end{array}$ \\
\hline Megalin & NM_001081088.1 & AAAATGGAAACGGGGTGACTT & GGCTGCATACATTGGGTTTTCA & 170 & 85 \\
\hline Cubilin & NM_001081084.2 & CACTTTAGGTTGTGGTGGAACA & TTGCTGTCAAAGCTAATCTCCC & 147 & 83 \\
\hline GAPDH & XM_001474390.1 & ACTCCACTCACGGCAAATTC & TCTCCATGGTGGTGAAGACA & 171 & 88 \\
\hline
\end{tabular}

(DAPI) (BioChemica A1001, AppliChem). The samples were examined with a Fluoview FV10i confocal microscope (Olympus). Negative controls without the corresponding primary antibody were used to observe tissue background. The scores of twenty randomly selected fields of renal cortex tubulointerstitium were averaged for each animal, and the scores of six separate animals were then averaged for each group. All the figures obtained were randomly chosen and blindly analyzed by the same nephrology specialist.

For the semiquantitative analysis of $\alpha$-SMA and MMP2 in the kidney, we established a score, modified from the method described by Ishidoya et al. (1995). Briefly, twenty random, non-overlapping fields of immunohistochemically labeled sections were assigned a score of zero to three. The score was based on the relation of the tubulointerstitium with the specific antibody where $0=$ changes affecting $<25 \%$ of the sample, $1=$ changes affecting $25 \%$ to $50 \%$ of the sample, 2 = changes affecting $50 \%$ to $75 \%$ of the sample, and 3 $=$ changes affecting $>75 \%$ of the sample (Benigni, A et al., 2004).
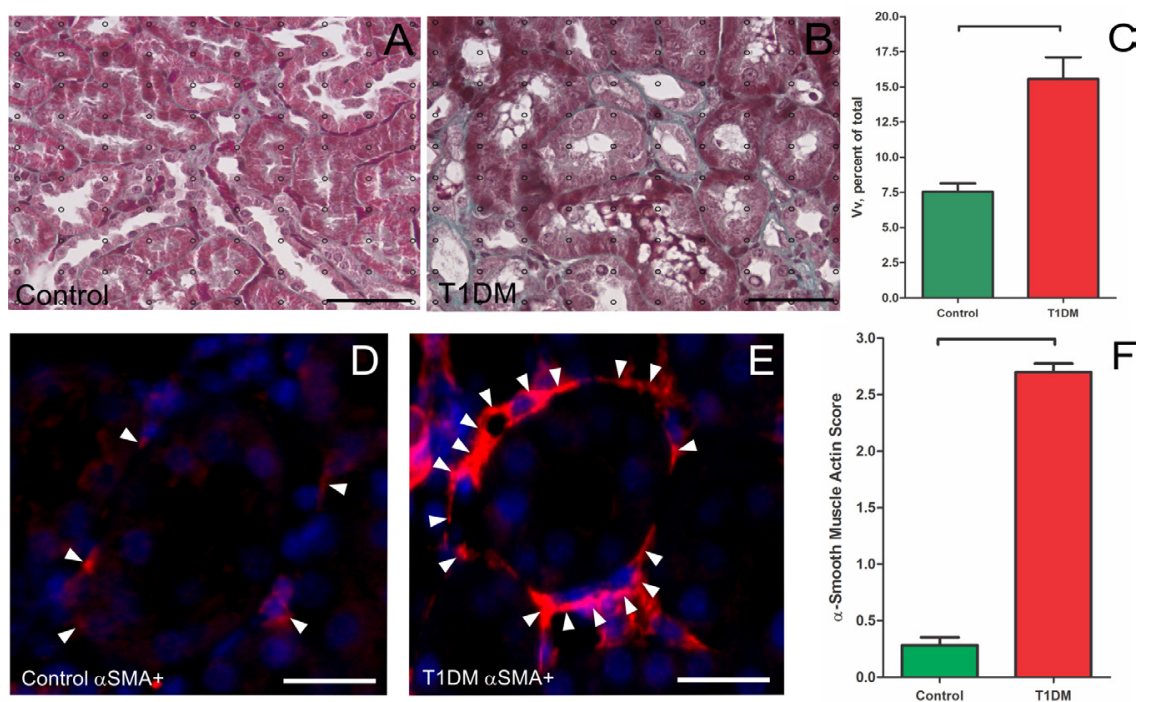

The immunoreactivity of megalin and cubilin was quantified using Image Pro-Plus $4.5^{\circledR}$ software (Media Cybernetics, Silver Spring, MA, USA) and the results were expressed as the percentage of positive megalin/cubilin tubular area. For the analysis of the co-expression of LBPA and megalin or cubilin, we used a score analogous to the one previously described, but exploring the entire kidney cortex in each case ( $\mathrm{N}=4$ for each experimental group) and assigning a score of $0=<25 \%$ of the proximal tubules show accumulation of LBPA-labeled vesicles, $1=25 \%$ to $50 \%$ of the tubules affected, 2 $=50 \%$ to $75 \%$ of tubules affected, and $3=>75 \%$ of alteration.

\section{Western blot (WB) analysis}

Immunoblot analysis was used to determine the total amount of megalin and cubilin receptors in the kidney and cubilin levels in urine. Tissue samples of kidney cortex were placed in ice-cold tissue protein extraction reagent (T-PER, Life Technologies) and homogenized. The homogenate was centrifuged at 10,500 rcf for 20 minutes at $4^{\circ} \mathrm{C}$. The supernatants were aliquoted and kept at $-80^{\circ} \mathrm{C}$

FIGURE 4. Evaluation of tubulointerstitial fibrosis in TIDM animals after 10 weeks of diabetes. (A-C) Relative volume (VV) of collagen deposition in the renal cortical interstitium (pointcounting technique - Masson trichrome staining method). (D-F) Immunofluorescence analysis of matrix score for alpha-smooth muscle actin ( $\alpha$-SMA, arrowheads) expression in renal cortical interstitium. Values are mean \pm SEM, $N=6$. Horizontal brackets indicate significant differences between TIDM and control groups (Student's t-test, $P<0.05$ ). Bars: $A$ and B: 50 um; D and E: $25 \mu \mathrm{m}$. 
until protein quantification. Loading buffer was mixed with the supernatant samples and boiled for 5 minutes before SDS-PAGE separation. Fifteen micrograms of protein from the kidney were loaded per lane. In all cases, the samples were separated by SDS-PAGE for 240 minutes at $40 \mathrm{~mA}$ and transferred onto a $0.2 \mu \mathrm{m}$ nitrocellulose membrane for 270 minutes at $90 \mathrm{~V}$. Prestained molecular mass markers were used to determine the migration of proteins onto the membrane. The nitrocellulose filter was then blocked for $2 \mathrm{~h}$ in TBS-T blocking buffer, followed by overnight incubation at $4^{\circ} \mathrm{C}$ with each of the primary antibodies diluted 1:500 in TBS-T. The primary antibodies used were the same as described above for IFI analysis. The secondary peroxidase-conjugated donkey anti-goat IgG antibody (Jackson) was diluted 1:5000 in TBS-T. The bound antibody was detected by its chemiluminescence and revealed in an autoradiography film (Sigma-Aldrich). Expression of each protein (tissue megalin or cubilin) was normalized to actin expression. For the case of cubilin present in urine, the results of densitometric quantifications were normalized to the creatinine concentration in urine samples. Densitometric semiquantification of protein bands was performed using $\mathrm{NIH}$ image analysis software. Results were expressed as mean \pm Standard Error of the Mean (SEM) for protein/actin or creatinine relative density units (RDU).

\section{Renal gene expression analysis}

Expression levels of megalin, cubilin, and GAPDH from kidney samples were assessed by quantitative RT-qPCR (details of specific primers were described in Table 1). Total RNA was purified using TRIzol (Invitrogen) and quantified spectrophotometrically at $260 \mathrm{~nm}$. One $\mu \mathrm{g}$ of total RNA was used for reverse transcription. Real time PCR was performed in a final volume of $10 \mu \mathrm{L}$ containing $50 \mathrm{ng}$ of cDNA, PCR LightCycler-DNA Master SYBRGreen reaction mix (Roche), $3 \mathrm{mM} \mathrm{MgCl} 2$, and $0.5 \mu \mathrm{M}$ of each specific primer (Supplementary Table 1) using a Light-Cycler thermocycler (Roche). To ensure that amplicons were from mRNA and not from genomic DNA amplification, controls without reverse transcription were included. Amplicon validation was performed based on their size and melting point. Relative quantification was performed using the $\Delta \Delta \mathrm{CT}$ method (Schmittgen, TD \& Livak, KJ, 2008). The mRNA levels of each target gene were normalized against the mRNA level of GAPDH and expressed as fold change versus normal mice.

\section{Statistical analysis}

The distribution of variables was first evaluated using a Kolmogorov-Smirnov normality test, and Bartlett's test for equal variances was used to evaluate homogeneity of variances for each set of experimental variables. The data were
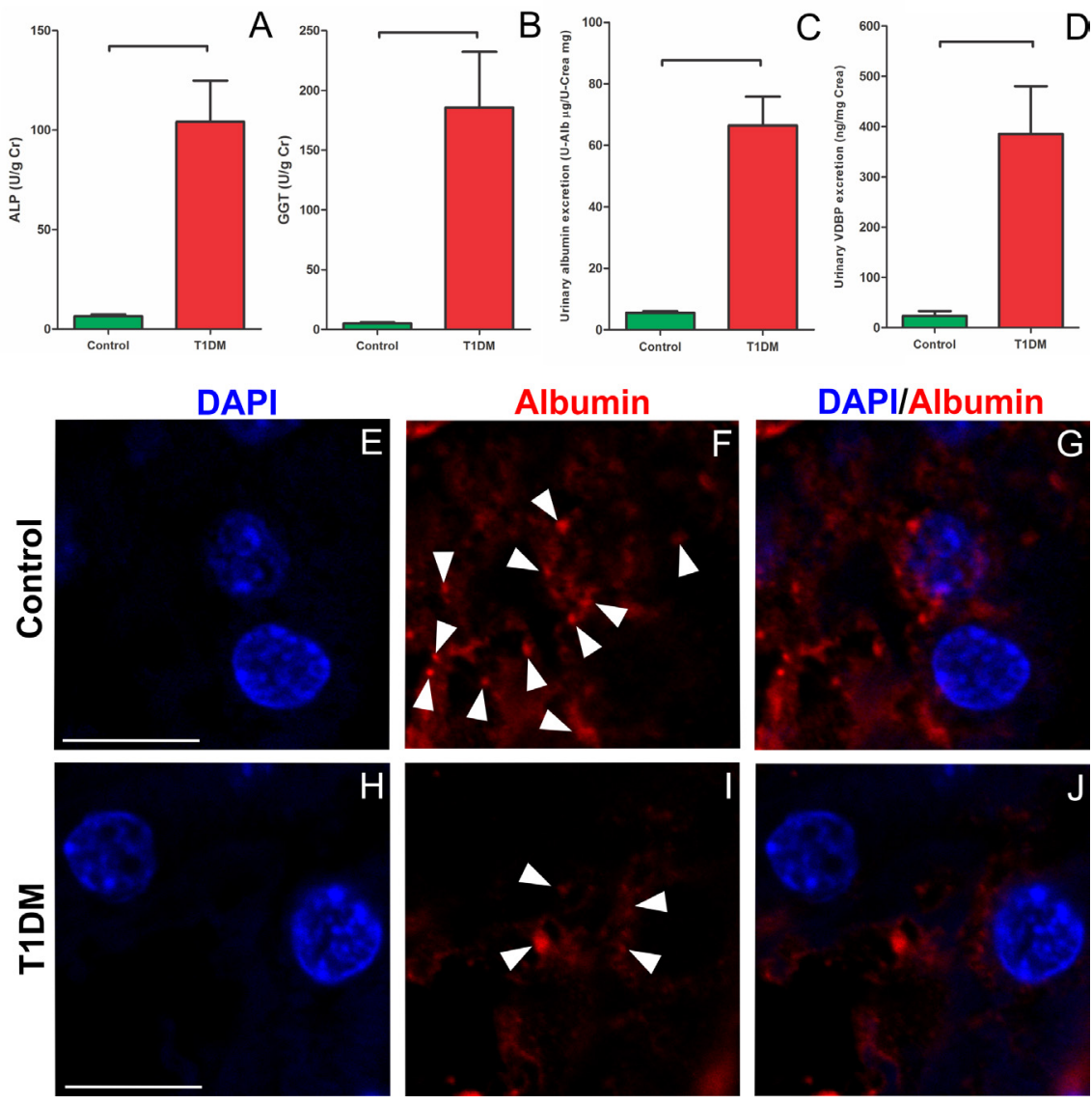

FIGURE 5. Evaluation of tubular function in TIDM animals after 10 weeks of diabetes. (A and B) Urinary excretion of tubular enzymes (ALP and GGT). (C) Albuminuria. (D) Urinary vitamin D-binding protein (VDBP) excretion. (E-J) Immunolabeled intracellular albumin (arrowheads) in kidney cortical tubules from control and TIDM animals. Values are mean $\pm \mathrm{SEM}, \mathrm{N}=6$. Horizontal brackets indicate significant differences between diabetic and control groups (Student's t-test, P<0.05). Bars: E-J: $10 \mu \mathrm{m}$. 
square-root transformed if variances differed significantly, and differences between groups of control and diabetic animals were evaluated by unpaired Student's t-test. Significance level was set at $\mathrm{P}<0.05$.

\section{Results}

\section{Diabetic nephropathy model}

After diabetes induction, hyperglycemia and body weight changes were observed in diabetic animals (Fig. 2 A and B).

Animals affected by diabetes showed a significant decrease in body weight compared with normal mice (Fig. 2 A). Also, blood glucose levels increased significantly after STZ administration in T1DM animals (Fig. 2 B). Ten weeks after diabetes induction, plasma insulin levels decreased by more than 95\% in T1DM animals when compared with controls (Fig. 2 C). On the other hand, kidney size in T1DM animals was significantly greater than that observed in the control group, as quantified by the renal mass index and kidney weight (Fig. 2 D and E).

Tubulointerstitial injury induced in early diabetic nephropathy One of the earliest morphological changes in diabetic nephropathy is the tubular thickening of basement membrane (Brito, PL et al., 1998; Fioretto, P \& Mauer, M, 2007; Singh,
DK \& Farrington, K, 2010). Under TEM, we observed a significant increase in the thickness of the tubular basement membrane (control: $236.7 \pm 19.0 \mu \mathrm{m}$ vs. T1DM: $381.3 \pm 36.8$ $\mu \mathrm{m}$; mean \pm SEM, Student $t$ - test) (Fig. $3 \mathrm{C}$ and D). We did not find significant microvilli alteration (Fig. $3 \mathrm{~A}$ and $\mathrm{B}$ ) and peritubular capillary rarefaction, as has been described previously, probably because of the early stage of the disease (Harris, RD et al., 1991). However, we found signs of interstitial fibrosis (analyzed below) and tubular atrophy with cellular alteration. Furthermore, we observed a marked increase in the amount of vesicles that showed characteristics of autophagosomes (Mizushima, N, 2004; Eskelinen, E-L et al., 2011; Klionsky, DJ et al., 2012), with a double membrane structure containing undigested cytoplasmic material including organelles such as mitochondria and lysosomes (Fig. 3 E-G and I). Also, a large amount of structures corresponding to secondary lysosomes and late endosomes were found in many tubules of diabetic nephropathy mice (see below, Fig. $3 \mathrm{H}$ and $\mathrm{J})$.

Tubulointerstitial injury in diabetic nephropathy animals was studied through structural parameters present during the progression of the disease. Initially, we explored the development of tubulointerstitial fibrosis via point counting. We observed a significant increase in the percentage of tubulointerstitial collagen deposits in T1DM
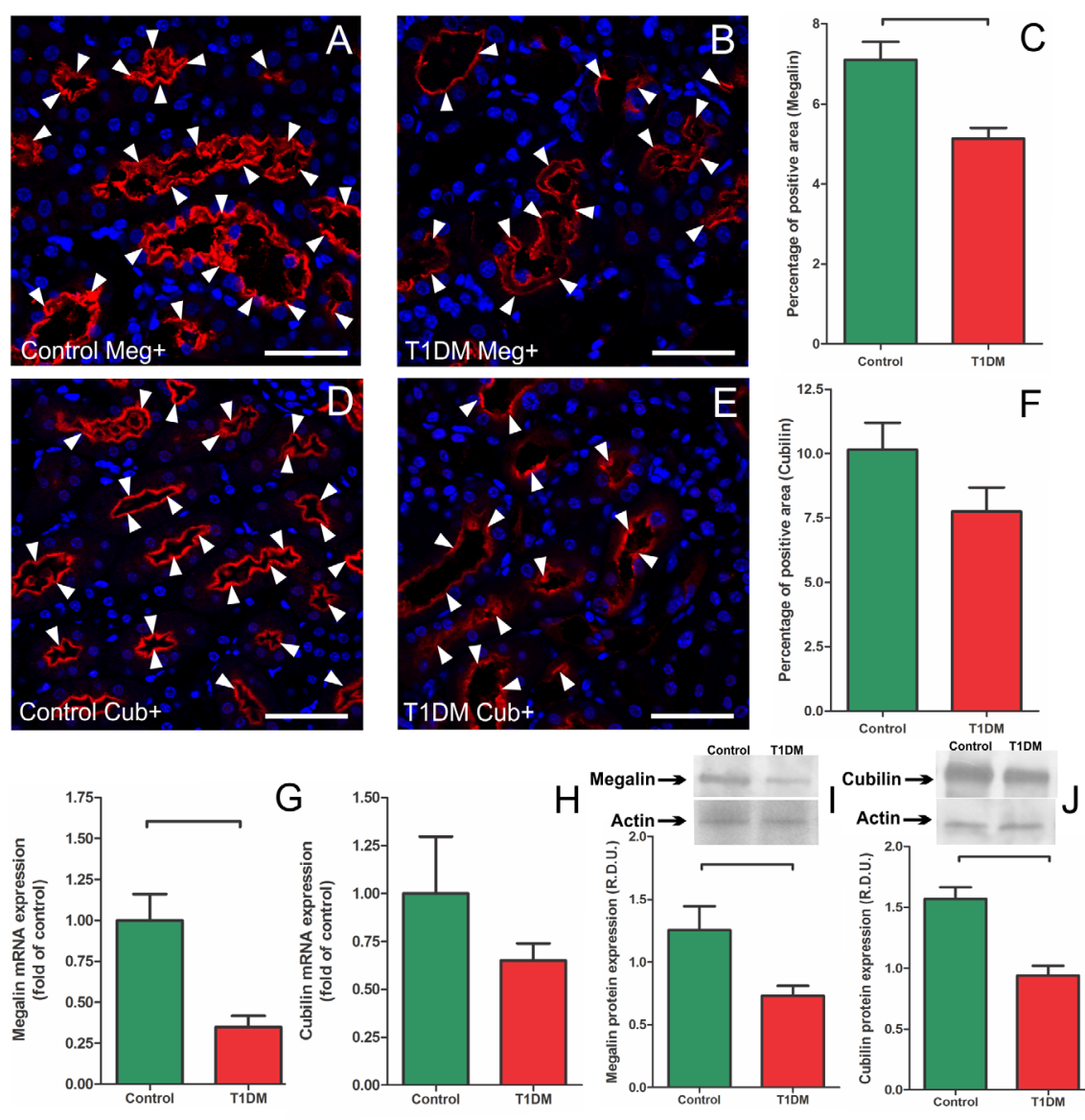

FIGURE 6. Analysis of protein tubular transporters megalin and cubilin in diabetic nephropathy induced after 10 weeks of TIDM. (A-C) Tubular megalin levels determined by immunofluorescence (arrowheads indicate megalin labeled brush border). (D-F) Tubular cubilin levels determined by immunofluorescence larrowheads indicate cubilin labeled brush border). ( $\mathbf{G}$ and $\mathbf{H}$ ) Quantitative megalin and cubilin RT-qPCR from the renal cortex (relative amount of megalin and cubilin mRNA was normalized to GAPDH mRNA expression). (I and J) Renal megalin and cubilin protein levels (measured by Western blot, RDU is relative density units of megalin or cubilin/ actin). Values are mean \pm SEM, $N=6$. Horizontal brackets indicate significant differences between TIDM and control groups (Student's t-test, $P<0.05)$. Bars: $A$ and $B, D$ and $E: 50 \mu m$. 
animals compared with controls (Fig. 4 A-C). Because the number of myofibroblasts is expected to increase during tubulointerstitial fibrosis in diabetic nephropathy, we analyzed their presence through the expression of alphasmooth muscle actin ( $\alpha$-SMA), observing a significant increase in the number of myofibroblasts located in the tubulointerstitium of T1DM animals (Fig. 4 D-F) compared with age-matched control mice.

As markers of proximal tubule injury, we first examined the urinary activity of ALP and GGT. Both enzymes were significantly increased in the urine of diabetic animals (Fig. $5 \mathrm{~A}$ and B) compared with the control group. Furthermore, we explored urinary albumin levels in T1DM and control animals, observing a significant increase after the development of diabetic nephropathy (Fig. 5 C). The observed urinary protein loss was probably related to the alteration of tubular endocytic transporters megalin and cubilin because of the significant increase in urinary excretion of VDBP in T1DM animals (Fig. 5 D), and also because of the decrease in intracellular albumin trafficking, evidenced by the reduction in labeled albumin in proximal tubule cells (Fig. 5 E-J).

\section{Megalin and cubilin in diabetic nephropathy induced by type 1 diabetes mellitus}

After the observation of tubular injury induced by diabetic nephropathy and the alteration of functional reabsorption as evidenced by the increased urinary levels of albumin and VDBP, we analyzed the specific proximal tubule protein transporters megalin and cubilin.

We observed a significant decrease in megalin mRNA expression (RT-qPCR) (Fig. $6 \mathrm{G}$ ) and its surface abundance
(IFI) (Fig. 6 A-C) in T1DM animals, as well as a not significant decrease in cubilin for the same parameters (Fig. $6 \mathrm{H}$ and D-F). We also found a significant decrease in the total amount of both proteins as determined by immunoblot (Fig. $6 \mathrm{I}$ and $\mathrm{J})$.

\section{Mechanisms involved in alteration of endocytic albumin} transporters

We studied two mechanisms that could be associated with the alteration of albumin transporters: malfunctioning of intracellular trafficking of megalin and cubilin and shedding of these transporters from the tubular brush border.

For the analysis of intracellular trafficking of both transporters, we analyzed the co-expression of megalin and cubilin with a marker of late endosomes (LBPA). We observed a markedly reduced expression of megalin and cubilin in the proximal tubule cells of T1DM animals (Fig. $7 \mathrm{~B}, \mathrm{D}, \mathrm{F}$, and H). LBPA-labeled vesicles were uniformly distributed on the surface of the proximal tubule epithelium of control animals (Fig. 7 A and C), but in T1DM animals the vesicles were increased and accumulated in regions of the tubule, and the superficial pattern observed in control animals was lost (Fig. $7 \mathrm{E}$ and G). Furthermore, we found that T1DM animals showed an increased number of tubules with this pattern of LBPA-labeled vesicles (Score $=$ Control: 0.75 vs. T1DM: 2.75 ).

Metalloprotease expression in the proximal tubule cells was increased in T1DM animals when compared to the controls (Fig. 8 A-C). In addition, we observed a not significant increase in urine albumin transporter levels (cubilin) in T1DM animals compared to control mice (Fig. 8 D).
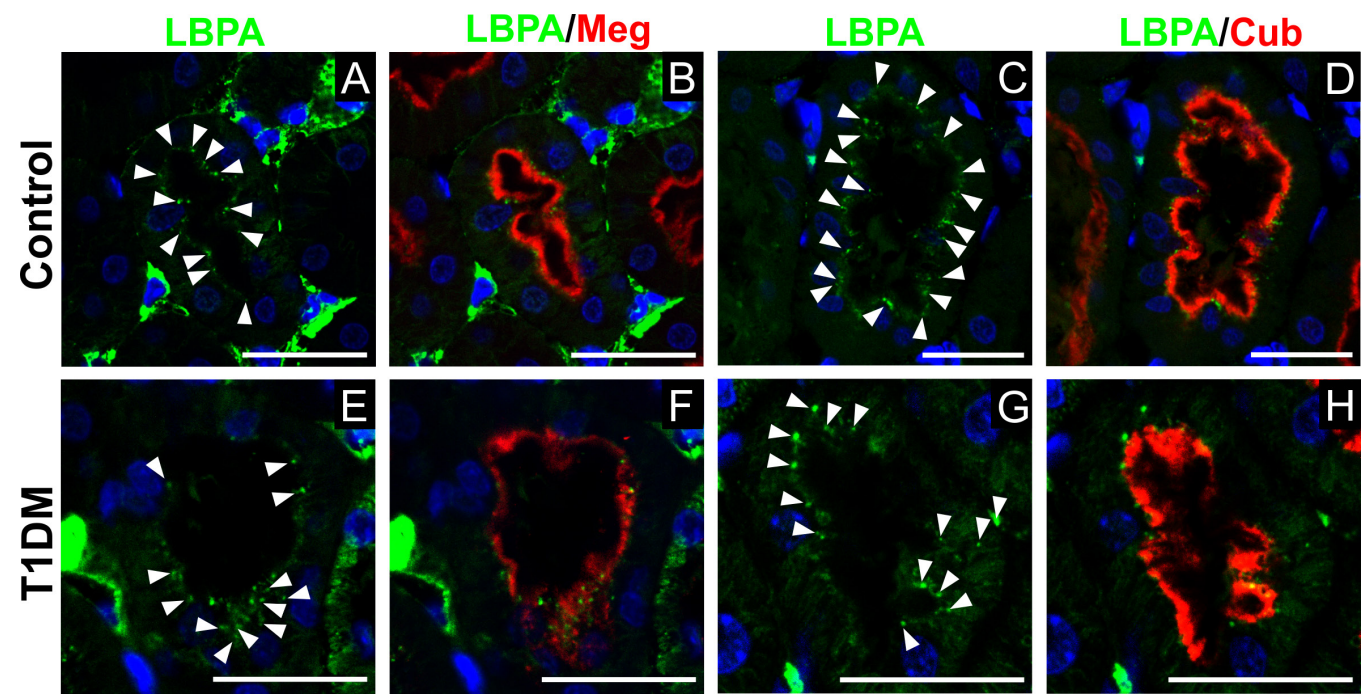

FIGURE 7. Evaluation of subcellular trafficking of albumin transporters (megalin and cubilin) in TIDM animals after 10 weeks of diabetes. Images from the upper panels show the presence of LBPA protein (arrowheads) and their co-localization with megalin and cubilin in control (A-D) and TIDM animals $(E-H)(N=4)$. Bars: $25 \mu \mathrm{m}$. 


\section{Discussion}

Proteinuria has classically been described as the hallmark of diabetic nephropathy (Moresco, RN et al., 2013). The characteristic pathological changes observed in diabetic nephropathy, such as the injury of glomerular endothelial cells, glomerular basement membrane, and podocytes, have an important role at advanced stages of diabetic nephropathy, but do not include all pathogenic mechanisms that cause proteinuria in diabetes mellitus (Jefferson, $J$ et al., 2008; Vallon, V, 2011; Vallon, V \& Komers, R, 2011). In a previous work (Ezquer, F et al., 2015), we observed that after 10 weeks of diabetes the animals showed a significant increase in albuminuria, but plasmatic creatinine levels, widely used to show signs of glomerular alteration and renal malfunction (Semedo, P et al., 2009), were not significantly different until after 16 weeks of disease. At the earliest stages of diabetes (10 weeks), the kidneys showed some podocyte alteration but the function of the glomeruli apparently remained unaltered with high levels of albuminuria. It is possible that other mechanisms usually overlooked, like the effect of tubulointerstitial injury over the proximal tubule albumin transport, could have a central role in trying to understand the mechanisms underlying proteinuria.

Indeed, proteinuria is not only a marker of the progression of renal disease, but also has an essential role in the pathogenesis of diabetic nephropathy (Abbate, $\mathrm{M}$ et al., 2006; Jefferson, J et al., 2008; Zoja, C et al., 2014). It has been demonstrated that the consequent protein reuptake throughout the nephron has stimulatory effects on the expression of pro-inflammatory and pro-fibrotic mediators in kidney tubular cells (Nath, KA, 1992; Tang, S et al., 2003), especially by the ability of albumin to act as a carrier of proinflammatory substances (Kamijo, A et al., 2002; Abbate, M et al., 2006; Urahama, Y et al., 2008). Albumin reabsorption has been shown to be reduced in early diabetic nephropathy (Tojo, A et al., 2001), but the underlying mechanisms are complex and not fully understood. In this work, we observed a significant increase in albuminuria in diabetic animals correlated with the development of tubulointerstitial fibrosis and the observation of tubular cell damage at an ultrastructural level. Furthermore, this pathological process was accompanied by tubular injury as evidenced by an increase in urinary enzyme excretion.

Recently, it has also been suggested that the function and/or expression of megalin and cubilin may be altered in the early stages of diabetic nephropathy (Saito, A et al., 2010). We observed that tubulointerstitial injury in T1DM goes hand in hand with the alteration of megalin and cubilin, which is involved in the physiologic uptake of proteins from the tubule. The ability of both transporters to reabsorb proteins (as demonstrated by VDBP transport and affectation in intracellular albumin trafficking) was reduced in
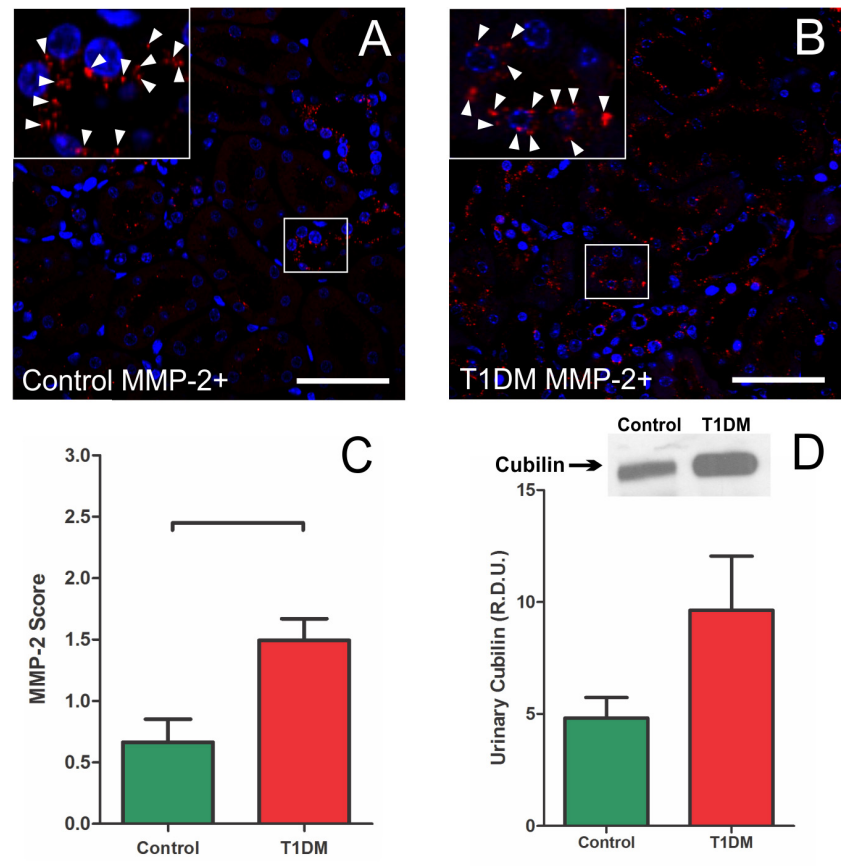

FIGURE 8. Evaluation of shedding of albumin transporters and their relationship with metalloprotease (MMP-2) expression in T1DM mice 10 weeks after diabetes induction. (A-C) Immunofluorescence analysis of MMP-2 levels (arrowheads) in kidney cortical tubules of control and T1DM animals. (D) Urinary excretion of protein transporters (cubilin) measured by Western blot. Values are mean \pm SEM, $N=6$. Horizontal brackets indicate significant differences between control and TIDM animals (Student's t-test, $P<0.05$ ). Bars: $A$ and B: $50 \mu \mathrm{m}$.

diabetic mice. Furthermore, protein and mRNA expression of megalin were clearly reduced in T1DM animals (as was the total amount of cubilin shown by immunoblot). In early stages of diabetic nephropathy in experimental animals, a decrease in megalin expression of proximal tubular cells has also been observed (Tojo, A et al., 2001; Yamashita, T et al., 2012). Likewise, protein reuptake has been related to high glucose levels in tubular cells (Ishibashi, F, 2004).

Autophagy is a catabolic process that maintains cellular homeostasis under intra- or extra-cellular stress conditions, helping cells to avoid apoptosis. Proximal tubule cell apoptosis was shown to contribute to tubular atrophy and glomerular-tubule disconnection during proteinuria (Benigni, A et al., 2001). Recent attention has been given to the participation of autophagy in the pathogenesis of diabetic nephropathy, essentially because of increasing evidence related to the impaired autophagic activity in diabetic kidney cells (Yamahara, K et al., 2013; Ding, Y \& Choi, ME, 2015). Furthermore, tubular epithelial cells show low levels of autophagy under physiological conditions (Liu, S et al., 2012). In our study, we observed an increase in the cellular degradative process in cells from the proximal tubules of T1DM animals, as shown by an increase in the relative number of tubules 


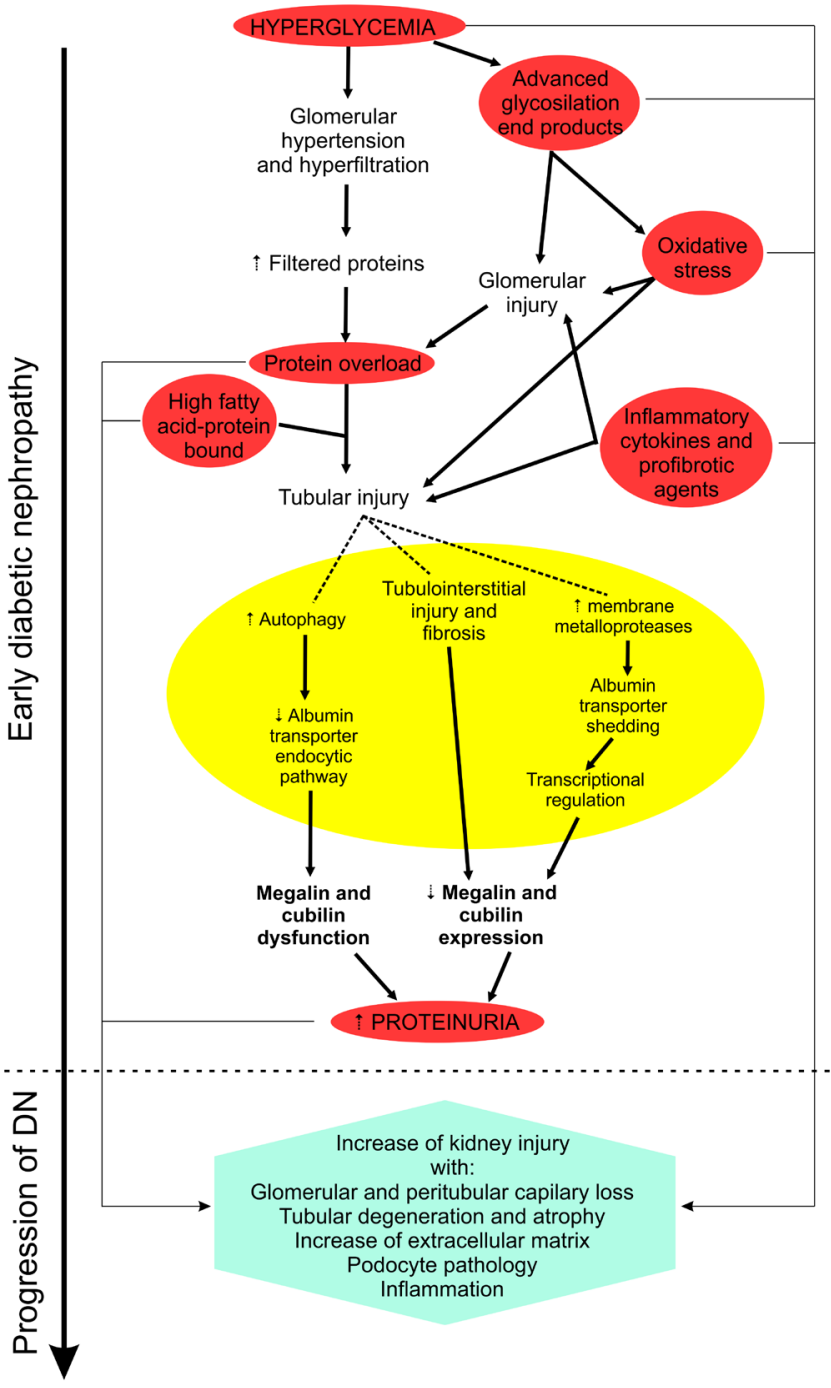

FIGURE 9. Proposed role of megalin and cubilin alteration during early diabetic nephropathy induced by type 1 diabetes mellitus. The multifactorial pathogenic mechanisms that induce glomerular and tubular injury produce an increase in albumin tubular levels that eventually affects the functionality and expression of megalin and cubilin. Injury of these transporters along with the other damaging effects of diabetes on the kidneys leads to progression of diabetic nephropathy.

from diabetic animals with numerous LBPA-labeled vesicles and many of these vesicles showed ultrastructural characteristics of autophagosomes. The alteration of the normal endocytic recycling pathway may be associated with the decrease in megalin and cubilin on the epithelial surface also observed in this work.

Another proposed mechanism linked to the alteration of proximal tubule albumin transporters is the shedding of receptors from the epithelial surface (Christensen, EI et al., 2012). The shedding of albumin transporters decreases the amount of available protein receptors and has also been associated with a direct decrease in protein synthesis as a consequence of an increase in the number of soluble fragments of this receptor trafficked to the nucleus, which could down-regulate gene expression (Biemesderfer, D, 2006). This could be related to the results we obtained for mRNA transporter expression. The increase in the urinary excretion of megalin, cubilin, and megalin fragments has been proposed as a marker of the progression of diabetic nephropathy (Thrailkill, KM et al., 2009; Ogasawara, S et al., 2012). As far as we know, while the presence of megalin and its fragments in urine has been reported previously, the presence of cubilin has not. In our study, we observed a significant increase in the presence of tubular metalloproteases in T1DM animals that could be associated with the shedding of albumin transporters. We found cubilin in the urine, but we did not discover significant differences when its levels were compared with controls. Our results, and the results previously described reporting the increase in urinary megalin in diabetic patients (Thrailkill, KM et al., 2009; Ogasawara, S et al., 2012), suggest that the shedding of megalin probably has a more important role as a pathogenic mechanism than that of cubilin. Likewise, our observations of the accumulation of LBPA-labeled vesicles in diabetic nephropathy tubules could contribute to the down-regulatory effect, and both mechanisms could contribute to the decrease in megalin and cubilin expression and to the renal dysfunction observed in our study.

The reduction in megalin expression and albumin endocytosis in T1DM rats with diabetic nephropathy was described almost 15 years ago (Tojo, A et al., 2001), but the question proposed by researchers about other possible mechanisms that could cause damage of the intracellular trafficking and degradation systems has not yet been completely clarified. In this work, we extensively explored albumin transport in the proximal tubule cells of early diabetic nephropathy in type 1 diabetic animals. The pathophysiological mechanisms involved in the development of diabetic nephropathy in T1DM animals is clearly related to a reduction in tubular protein reabsorption associated with tubulointerstitial injury and fibrosis, with an increase of cellular metalloproteases (Fig. 9). Both of these mechanisms induce a decrease in the expression of megalin and cubilin in T1DM animals at early stages of diabetic nephropathy (Fig. 9), which could be related to the significant increase in albumin and VDBP urinary excretion. We also observed another recently described pathophysiological mechanism that could be associated with tubular injury, i.e., the increase in the amount of vesicles from the phagocytic system in the proximal tubule. The alteration of the autophagic machinery in diabetic tubular cells could partially explain the malfunction of megalin and cubilin albumin transporters that could be linked to the development and progression of proteinuria (Fig. 9). The alteration of megalin and cubilin at early stages of diabetic nephropathy could contribute to the other pathogenic mechanisms acting during the evolution of diabetic nephropathy to induce progressive kidney damage (Fig. 9).

We hope that our work will begin to enlighten the tubular intracellular mechanisms affected by diabetic nephropathy, 
with special focus on proteinuria, and that this growing field of study will help researchers find new therapeutics directed at preventing the development of diabetic kidney disease.

\section{Acknowledgements}

The authors thank Dr. Claudio Fader (IHEM-CONICET) for the generous help provided for the evaluation of endocytosis in control and diabetic kidney tubules, and Dr. Alfonsina Morales (IHEM-CONICET) for her generous collaboration in ultrastructural analysis. This work was supported by Grant FONDECyT PD2014 [3140024] to Maximiliano Giraud-Billoud.

\section{References}

Abbate, M, Zoja C, Remuzzi, G (2006). How does proteinuria cause progressive renal damage? Journal of the American Society of Nephrology: JASN 17: 2974-2984.

Alpers, CE, Hudkins, KL (2011). Mouse models of diabetic nephropathy. Current Opinion in Nephrology and Hypertension 20: 278-285.

Amiri F, Shaw S, Wang X, Tang J, Waller JL, Eaton DC, Marrero MB (2002). Angiotensin II activation of the JAK/STAT pathway in mesangial cells is altered by high glucose. Kidney International 61: 1605-1616.

Benigni A, Gagliardini E, Remuzzi A, Corna D, Remuzzi G (2001). Angiotensin-Converting Enzyme nhibition Prevents GlomerularTubule Disconnection and Atrophy in Passive Heymann Nephritis, an Effect Not Observed with a Calcium Antagonist. The American Journal of Pathology 159: 1743-1750.

Benigni A, Zoja C, Zatelli C, Corna D, Longaretti L, Rottoli D, Maggioni P, Todeschini M, Noris M, Remuzzi, G (2004). Vasopeptidase inhibitor restores the balance of vasoactive hormones in progressive nephropathy. Kidney International 66: 1959-1965.

Biemesderfer D (2006). Regulated intramembrane proteolysis of megalin: linking urinary protein and gene regulation in proximal tubule? Kidney International 69: 1717-1721.

Blantz RC, Singh P (2014). Glomerular and tubular function in the diabetic kidney. Advances in Chronic Kidney Disease 21: 297-303.

Bourdeau J, Carone F (1974). Protein handling by the renal tubule. Nephron 13: 22-34.

Bradford MM (1976). A rapid and sensitive method for the quantitation of microgram quantities of protein utilizing the principle of proteindye binding. Analytical Biochemistry 72: 248-254.

Breyer MD, Böttinger E, Brosius 3rd F, Coffman TM, Harris RC, Heilig CW, Sharma K (2005). Mouse models of diabetic nephropathy. Journal of the American Society of Nephrology: JASN 16: 27-45.

Brito PL, Fioretto P, Drummond K, Kim Y, Steffes MW, Basgen JM, SissonRoss S, Mauer, M (1998). Proximal tubular basement membrane width in insulin-dependent diabetes mellitus. Kidney International 53: 754-761.

Caruso-Neves C, Pinheiro AaS, Cai H, Souza-Menezes J, Guggino, WB (2006). PKB and megalin determine the survival or death of renal proximal tubule cells. Proceedings of the National Academy of Sciences of the United States of America 103: 18810-18815.
Coudroy G, Gburek J, Kozyraki R, Madsen M, Trugnan G, Moestrup SK, Verroust PJ, Maurice, $\mathrm{M}$ (2005). Contribution of cubilin and amnionless to processing and membrane targeting of cubilin-amnionless complex. Journal of the American Society of Nephrology: JASN 16: 2330-2337.

Christensen EI, Birn H (2001). Megalin and cubilin: synergistic endocytic receptors in renal proximal tubule. American journal of physiology. Renal Physiology 280: F562-F573.

Christensen EI, Birn H, Storm T, Weyer K, Nielsen R (2012). Endocytic receptors in the renal proximal tubule. Physiology 27: 223-236.

Christensen EI, Nielsen R, Birn H (2013). From bowel to kidneys: the role of cubilin in physiology and disease. Nephrology Dialysis Transplantation 28: $274-281$.

Ding Y, Choi ME (2015). Autophagy in diabetic nephropathy. The Journal of Endocrinology 224: R15-R30.

Efendiev R, Budu CE, Cinelli AR, Bertorello AM, Pedemonte CH (2003). Intracellular $\mathrm{Na}+$ regulates dopamine and angiotensin II receptors availability at the plasma membrane and their cellular responses in renal epithelia. Journal of Biological Chemistry 278: 28719-28726.

Eskelinen E-L, Reggiori F, Baba M, Kovács AL, Seglen PO (2011). Seeing is believing: the impact of electron microscopy on autophagy research. Autophagy 7: 935-956.

Ezquer F, Ezquer M, Simon V, Pardo F, Yaņez A, Carpio D, Conget P (2009). Endovenous administration of bone marrow-derived multipotent mesenchymal stromal cells prevents renal failure in diabetic mice. Biology of Blood and Marrow Transplantation 15: 1354-1365.

Ezquer F, Giraud-Billoud M, Carpio D, Cabeza F, Conget P, Ezquer M (2015). Pro-regenerative microenvironment triggered by donor mesenchymal stem cells preserves renal function and structure in mice with severe Diabetes Mellitus. BioMed Research International 2015, Article ID 164703: 23.

Fioretto P, Mauer M (2007). Histopathology of diabetic nephropathy. Seminars in Nephrology 27: 195-207.

Gibb D, Tomlinson P, Dalton N, Turner C, Shah V, Barratt T (1989). Renal tubular proteinuria and microalbuminuria in diabetic patients. $A r$ chives of Disease in Childhood 64: 129-134.

Gross JL, De Azevedo MJ, Silveiro SP, Canani LH, Caramori ML, Zelmanovitz T (2005). Diabetic nephropathy: diagnosis, prevention, and treatment. Diabetes Care 28: 164-176.

Hammad SM, Barth JL, Knaak C, Argraves WS (2000). Megalin acts in concert with cubilin to mediate endocytosis of high density lipoproteins. Journal of Biological Chemistry 275: 12003-12008.

Harris RD, Steffes MW, Bilous RW, Sutherland D, Mauer SM (1991). Global glomerular sclerosis and glomerular arteriolar hyalinosis in insulin dependent diabetes. Kidney International 40: 107-114.

Hong CY, Chia KS (1998). Markers of diabetic nephropathy. Journal of Diabetes and its Complications 12: 43-60.

Huang H-C, Preisig PA (2000). G1 kinases and transforming growth factor-\&bgr; signaling are associated with a growth pattern switch in diabetes-induced renal growth. Kidney International 58: 162-172.

Ishibashi F (2004). High glucose reduces albumin uptake in cultured proximal tubular cells (LLC-PK1). Diabetes Research and Clinical Practice 65: 217-225.

Ishidoya S, Morrissey J, Mccracken R, Reyes A, Klahr S (1995). Angiotensin II receptor antagonist ameliorates renal tubulointerstitial fibrosis caused by unilateral ureteral obstruction. Kidney International 47: 1285-1294.

Jefferson J, Shankland S, Pichler R (2008). Proteinuria in diabetic kidney disease: a mechanistic viewpoint. Kidney International 74: 22-36.

Kamijo A, Kimura K, Sugaya T, Yamanouchi M, Hase H, Kaneko T, Hirata Y, Goto A, Fujita T, Omata M (2002). Urinary free fatty acids bound to albumin aggravate tubulointerstitial damage. Kidney International 62: 1628-1637. 
Kanasaki K, Taduri G, Koya D (2013). Diabetic nephropathy: the role of inflammation in fibroblast activation and kidney fibrosis. Frontiers in Endocrinology 4: 1-15.

Kanwar YS, Wada J, Sun L, Xie P, Wallner EI, Chen S, Chugh S, Danesh FR (2008). Diabetic nephropathy: mechanisms of renal disease progression. Experimental Biology and Medicine 233: 4-11.

Katoh M, Ohmachi Y, Kurosawa Y, Yoneda H, Tanaka N, Narita H (2000) Effects of imidapril and captopril on streptozotocin-induced diabetic nephropathyinmice.European JournalofPharmacology398:381-387.

Klionsky DJ, Abdalla FC, Abeliovich H, Abraham RT, Acevedo-Arozena A, Adeli K, Agholme L, Agnello M, Agostinis P, Aguirre-Ghiso JA (2012). Guidelines for the use and interpretation of assays for monitoring autophagy. Autophagy 8: 445-544.

Lane PH, Steffes MW, Fioretto P, Mauer SM (1993). Renal interstitial expansion in insulin-dependent diabetes mellitus. Kidney International 43: 661-661.

Liu S, Hartleben B, Kretz O, Wiech T, Igarashi P, Mizushima N, Walz G Huber TB (2012). Autophagy plays a critical role in kidney tubule maintenance, aging and ischemia-reperfusion injury. Autophagy $\mathbf{8}$ 826-837.

Loeffler I(2012). Pathophysiology of diabetic nephropathy. In:Diabetes and KidneyDisease: (Wolf, G, ed), p.45. Wiley-Blackwell, Jena, Germany.

Meyer TW (2003). Tubular injury in glomerular disease. Kidney International 63: 774-787.

Mizushima N (2004). Methods for monitoring autophagy. The International Journal of Biochemistry and Cell Biology 36: 2491-2502.

Møller JC, Skriver E (1985). Quantitative ultrastructure of human proximal tubules and cortical interstitium in chronic renal disease (hydronephrosis). Virchows Archiv. A, Pathological Anatomy and Histopathology 406: 389-406.

Moresco RN, Sangoi MB, De Carvalho JA, Tatsch E, Bochi GV (2013) Diabetic nephropathy: traditional to proteomic markers. Clinica Chimica Acta 421: 17-30.

Nath KA (1992). Tubulointerstitial changes as a major determinant in the progression of renal damage. American Journal of Kidney Diseases 20: 1-17.

Nielsen R, Christensen EI, Birn H (2016). Megalin and cubilin in proxima tubule protein reabsorption: from experimental models to human disease. Kidney International 89: 58-67.

Ogasawara S, Hosojima M, Kaseda R, Kabasawa H, Yamamoto-Kabasawa K, Kurosawa H, Sato H, Iino N, Takeda T, Suzuki Y (2012). Significance of urinary full-length and ectodomain forms of megalin in patients with type 2 diabetes. Diabetes Care 35: 1112-1118.

Raab WP (1972). Diagnostic value of urinary enzyme determinations. Clinical Chemistry 18: 5-25

Saito, A, Kaseda, R, Hosojima, M \& Sato, H. 2010. Proximal tubule cell hypothesis for cardiorenal syndrome in diabetes. International Journal of Nephrology 2011: 1-9.

Schmittgen TD, Livak KJ (2008). Analyzing real-time PCR data by the comparative CT method. Nature Protocols 3: 1101-1108.

Semedo P, Correa-Costa M, Antonio Cenedeze M, Maria Avancini Costa Malheiros D, Antonia Dos Reis M, Shimizu MH, Seguro AC, Pacheco-Silva A, Saraiva Ĉamara NO (2009). Mesenchymal stem cells attenuate renal fibrosis through immune modulation and remodeling properties in a rat remnant kidney model. Stem Cells 27: 3063-3073.

Singh DK, Farrington K (2010). The tubulointerstitium in early diabetic nephropathy: Prime target or bystander? International Journal of Diabetes in Developing Countries 30: 185-190.

Szasz G (1969). A kinetic photometric method for serum $\gamma$-glutamyl transpeptidase. Clinical Chemistry 15: 124-136.
Tang S, Leung JC, Abe K, Chan KW, Chan LY, Chan TM, Lai KN (2003). Albumin stimulates interleukin-8 expression in proximal tubular epithelial cells in vitro and in vivo. The Journal of Clinical Investigation 111: 515-527.

Tay YC, Wang Y, Kairaitis L, Rangan GK, Zhang C, Harris, DCH (2005). Can murine diabetic nephropathy be separated from superimposed acute renal failure\&quest. Kidney International 68: 391-398.

Tesch GH, Nikolic-Paterson DJ (2006). Recent insights into experimental mouse models of diabetic nephropathy. Nephron. Experimental Nephrology 104: e57-e62.

Thrailkill KM, Nimmo T, Bunn RC, Cockrell GE, Moreau CS, Mackintosh S, Edmondson RD, Fowlkes JL (2009). Microalbuminuria in type 1 diabetes is associated with enhanced excretion of the endocytic multiligand receptors megalin and cubilin. Diabetes Care 32: 1266-1268.

Tietz N, Rinker A, Shaw L (1983). IFCC methods for the measurement of catalytic concentration of enzymes Part 5. IFCC method for alkaline phosphatase (orthophosphoric-monoester phosphohydrolase, alkaline optimum, EC 3.1. 3.1). Journal of Clinical Chemistry and Clinical Biochemistry 21: 731-748.

Tojo A, Onozato M, Ha H, Kurihara H, Sakai T, Goto A, Fujita T, Endou $\mathrm{H}$ (2001). Reduced albumin reabsorption in the proximal tubule of early-stage diabetic rats. Histochemistry and Cell Biology 116: 269-276.

Tojo A, Onozato M, Kurihara H, Sakai T, Goto A, Fujita T (2003). Angiotensin II blockade restores albumin reabsorption in the proximal tubules of diabetic rats. Hypertension Research 26: 413-419.

Urahama Y, Ohsaki Y, Fujita Y, Maruyama S, Yuzawa Y, Matsuo S, Fujimoto $\mathrm{T}$ (2008). Lipid droplet-associated proteins protect renal tubular cells from fatty acid-induced apoptosis. The American Journal of Pathology 173: $1286-1294$

Vallon V. 2011. The proximal tubule in the pathophysiology of the diabetic kidney. American Journal of Physiology. Regulatory, Integrative and Comparative Physiology 300: R1009-R1022.

Vallon V, Komers R (2011). Pathophysiology of the diabetic kidney. Comprehensive Physiology 1: 1175-1232.

Vallon V, Thomson SC (2012). Renal function in diabetic disease models: the tubular system in the pathophysiology of the diabetic kidney. Annual Review of Physiology 74: 1-27.

Vallon V (2014). Do Tubular Changes in the Diabetic Kidney Affect the Susceptibility to Acute Kidney Injury. Nephron. Clinical Practice 127: 133-138.

Whaley-Connell A, Habibi J, Panfili Z, Hayden MR, Bagree S, Nistala R, Hyder S, Krueger B, Demarco V, Pulakat L (2011). Angiotensin II activation of mTOR results in tubulointerstitial fibrosis through loss of N-cadherin. American Journal of Nephrology 34: 115-125.

White KE, Bilous RW (2000). Type 2 diabetic patients with nephropathy show structural-functional relationships that are similar to type 1 disease. Journal of the American Society of Nephrology: JASN 11: 1667-1673

Yamahara K, Yasuda M, Kume S, Koya D, Maegawa H, Uzu T (2013). The role of autophagy in the pathogenesis of diabetic nephropathy. Journal of Diabetes Research 2013, Article ID 193757: 9.

Yamashita T, Fujimiya M, Nagaishi K, Ataka K, Tanaka M, Yoshida H, Tsuchihashi K, Shimamoto K, Miura T (2012). Fusion of bone marrowderived cells with renal tubules contributes to renal dysfunction in diabetic nephropathy. FASEB Journal 26: 1559-1568.

Zoja C, Abbate M, Remuzzi G (2014). Progression of renal injury toward interstitial inflammation and glomerular sclerosis is dependent on abnormal protein filtration. Nephrology Dialysis Transplantation: 1-7. 